\title{
COVID-19 Inspired Relational Telemental Health Services for Incarcerated Individuals and Their Families
}

\author{
Eman Tadros ${ }^{1} \mathbb{D} \cdot$ Noemi Aguirre $^{2} \cdot$ Sarah Jensen $^{3} \cdot$ Julie Poehlmann-Tynan $^{3}$
}

Accepted: 6 April 2021 / Published online: 18 April 2021

(c) The Author(s), under exclusive licence to Springer Science+Business Media, LLC, part of Springer Nature 2021

\begin{abstract}
The novel coronavirus pandemic has caused marriage and family therapists (MFTs) to alter how they provide clinical services. MFTs must determine how to deliver relationship-oriented services to underserved populations that are often forgotten during crises, including incarcerated individuals and their families. The primary purpose of this paper is to showcase how relational telemental health (TMH) services for incarcerated individuals and their families can increase access to services and improve relational health. Information is presented about corrections in the U.S., effects of incarceration on partners, children, and other family members, the behavioral health and relationship needs of incarcerated individuals, and current approaches to relational mental health and telehealth in corrections. Finally, suggestions are offered on how relational TMH could be used in corrections during the COVID-19 pandemic, including advocacy for collaborative healthcare, recommended implementation practices, and ethical considerations.
\end{abstract}

Keywords COVID-19 $\cdot$ Incarceration $\cdot$ Relational therapy $\cdot$ Telehealth

The quarantine caused by the novel coronavirus (SARSCoV-2) pandemic has prompted mental health professionals to change the way they provide clinical services, with telemental health (TMH) going from a special mode of treatment delivery to a typical protocol. Telehealth, which originated at National Aeronautics and Space Administration (NASA) in the early days of the space program, involves the electronic exchange of medical information designed to promote the health and well-being of individuals (Simpson et al., 2013) (Table 1). Relational telehealth-also referred to as online therapy or e-therapy-is the electronic modality utilized to conceptualize relationships and mental health systemically to support the well-being and functioning of individuals, couples, parent-child dyads, and families (Wrape \& McGinn, 2019). Telehealth can include services provided by professionals such as psychiatrists, psychologists, counselors, marriage and family therapists (MFTs), and social workers.

Eman Tadros

emantadros@gmail.com

1 Governors State University, University Park, IL, USA

2 Northwestern University, Evanston, IL, USA

3 University of Wisconsin-Madison, Madison, WI, USA

\section{Implications of COVID-19 for Mental and Relational Health in Correctional Settings}

The United States (U.S.) is the world leader in mass incarceration (Sawyer \& Wagner, 2020). At any given time in the U.S., 1.3 million people are incarcerated in state and 230,000 in federal prisons, which hold individuals convicted of felonies, usually for more than a year (Sawyer \& Wagner, 2020). Yet the U.S. has seen more than 10 million annual admissions to jails (Zeng, 2020), which are locally run corrections facilities that hold people who are detained, awaiting conviction or sentencing, or serving sentences for misdemeanor crimes, usually for relatively short periods of time. COVID-19 was declared a pandemic on March 11, 2020 by the World Health Organization (WHO; Riad et al., 2020), and by May 2020, the WHO reported 4.2 million confirmed cases and 302,059 deaths. Lack of scientific research on COVID-19 led to non-pharmacologic interventions like quarantine, isolation, social distancing, and hygienic protocols (Riad et al., 2020). Similar to other health outbreaks such as Ebola, the Severe Acute Respiratory System, and Zika, COVID19 is perceived as a traumatic event that increases anxiety, fear, and depression (Riad et al., 2020). Furthermore, 
Table 1 Recommendations for relational TMH in correctional settings

\begin{tabular}{|c|c|}
\hline crease access to care & $\begin{array}{l}\text { Implement relational TMH in jails and prisons already equipped with computers, tablets, and internet } \\
\text { access for staff } \\
\text { Offer relational TMH connections at low cost or free } \\
\text { Integrate relational TMH with other family-oriented, parenting, or mental health programs } \\
\text { Allow higher-risk individuals access to relational TMH } \\
\text { Connect families living far from corrections facilities as a more routine process } \\
\text { Communicate the convenience and other benefits for therapists to increase the number of profession- } \\
\text { als offering relational TMH }\end{array}$ \\
\hline Provide collaborative care & $\begin{array}{l}\text { Practice unique skills for treatment planning in collaboration with other healthcare professionals } \\
\text { Acknowledge established links among family relationships, physical health, and mental health } \\
\text { Acknowledge established links among family relationships and reentry success } \\
\text { Coordinate efforts to improve healthcare access and delivery across healthcare disciplines } \\
\text { Combine efforts to increase health justice }\end{array}$ \\
\hline $\begin{array}{l}\text { Consider special issues when implement- } \\
\text { ing relational TMH in corrections } \\
\text { settings }\end{array}$ & $\begin{array}{l}\text { Identify or develop resources to treat incarcerated individuals and their families using relational TMH } \\
\text { Access free TMH platforms } \\
\text { Provide privacy for relational TMH for nonviolent offenders } \\
\text { Protect client confidentiality in jail and prison settings } \\
\text { Collect data to determine usefulness of relational TMH for institutional behavior, mental health, and } \\
\text { recidivism }\end{array}$ \\
\hline Ethical issues & $\begin{array}{l}\text { Address barriers to relational TMH in the criminal justice system including cost, technology, stigma, } \\
\text { family conflict, and decreased family communication because of the pandemic } \\
\text { Identify and implement informed consent as an ongoing process } \\
\text { Help MFTs gain access to ethical and legal guides on technology usage in therapy } \\
\text { Help MFTs access cross-state certifications }\end{array}$ \\
\hline
\end{tabular}

COVID-19 has spread rapidly in correctional facilities, and in April of 2020, eight of the ten largest virus outbreaks in the U.S. occurred in jails or prisons (Srikanth, 2020). By February 2021, there were 381,400 confirmed cases in prison with COVID-19 (The Marshall Project, 2021). The disproportionate concentration of cases in correctional facilities increases the likelihood that incarcerated individuals and their family members will experience the increased anxiety, fear, and depression that has been documented in the general population (Hawks et al., 2020; Stark et al., 2020). Furthermore, because in-person visits have been suspended in many correctional facilities due to the virus (Prison Policy Initiative, 2020), family members likely experience more difficulties and decreases in communication with their incarcerated loved ones.

During the COVID-19 pandemic, most corrections facilities in the U.S. have eliminated in-person programs and visits to protect the health of incarcerated individuals and corrections staff because the virus spreads rapidly in confined settings such as jails, prisons, and nursing homes (Miller \& Blumstein, 2020; Williams \& Ivory, 2020). Ceasing visitation is additionally concerning due to its implications on recidivism; it has been found that visitation has served to reduce recidivism (Mitchell et al., 2016). Aiding incarcerated individuals in connecting with their families is vital to strengthening family relationships during the pandemic, when many people experience additional stressors. Given the contagiousness of the virus and limited treatment options, corrections systems need to find new ways to meet the health, mental health, and relationship needs of incarcerated individuals and their families.

\section{Impact of Incarceration on Families and Children}

Many parents, partners, and siblings are left to face the burdens of having a loved one incarcerated, such as financial strain, residential instability, relationship dissolution, and stigma (Datchi \& Sexton, 2013; Gueta, 2018; Tadros, Fye, et al., 2020; Tadros et al., 2021). For example, the parents of incarcerated individuals frequently suffer from stress, financial hardship, and guilt, and they often struggle with a feeling of failure as a parent (Gueta, 2018). When a partner or parent is incarcerated, relationship dynamics are typically disrupted, which can lead to conflicts in family relationships (Datchi \& Sexton, 2013; DeHart et al., 2018; Tadros \& Ogden, 2020; Tadros, Fye, et al., 2020). In addition, about 5 million children in the U.S. have experienced having a parent in jail or prison (Murphey \& Cooper, 2015). Many studies have documented increased risk for less optimal behaviors, mental health, and academic outcomes in children with incarcerated parents relative to their peers (e.g., Turney \& Haskins, 2019). Children and adolescents with incarcerated parents are more likely to suffer from depression, anger, and anxiety and exhibit more aggression, substance use, and school problems compared to those who have never experienced the incarceration of a parent (Haskins, 2014, 2015; 
Turney \& Haskins, 2014; Wildeman, 2010). Further, many children face trauma from the time of their parent's arrest through their release (Arditti \& Salva, 2015).

Many incarcerated individuals express the desire to maintain relationships with their children and partner (Comfort et al., 2016; Hairston, 1991). However, staying engaged with children is a challenge for many incarcerated parents (e.g., McKay et al., 2019). Familial relations may be further strained as prisons can be located far away from families, have rigid visiting restrictions, and more institutions are moving toward video messaging and away from in-person visiting (Comfort et al., 2016; Skora Horgan \& PoehlmannTynan, 2020), a trend that may accelerate due to the onset of COVID-19.

\section{Benefits of Telemental Health During COVID-19}

When infectious diseases arise that require people to stay home, domestic relational conflict (van Gelder et al., 2020) and child abuse severity increase (Peterman et al., 2020). Loss of social interaction can lead to less life satisfaction, resulting in depression or anxiety and negative interactions with others (Yan et al., 2019). Due to this, the promotion of social inclusion through technology in a time of home confinement and isolation is critical (Ammar et al., 2020). Technology in the healthcare field is proving to be vital in maintaining social distancing restrictions (Smith et al., 2020), as well as treating physical, behavioral, emotional, and relational health concerns (Springer et al., 2020). These conditions include panic disorders, depression, anxiety, relationship problems, and family conflict (Doss et al., 2017; Hertlein et al., 2014), all of which are prevalent during this pandemic. Widespread use of technology in the U.S., such as through computers and smartphones, combined with new media, have expanded how people communicate and who can be reached (Hertlein et al., 2014). TMH now allows MFTs to reach a wide range of people, including those in remote and rural areas (Perle \& Nierenberg, 2013).

Currently, relational TMH services include both family and couples therapy, using websites and video-conferencing software (Gassova \& Werner-Wilson, 2018). Growing evidence suggests that different therapeutic models can be implemented effectively within the context of online therapy (Springer et al., 2020). Case studies focusing on electronic relational therapeutic services suggest that TMH is wellreceived by clients (Comer et al., 2017; Dausch et al., 2009; Hill et al., 2001; Wrape \& McGin, 2019). Findings indicated that satisfaction levels and participation were the same for virtual and clinic-based treatment, but virtual therapy eliminated transportation issues (Comer et al., 2017). Despite its promise, however, the effectiveness of relational TMH services is understudied, as most TMH research has focused on individual therapy (Wrape \& McGinn, 2019).

\section{TMH Application to Corrections}

Mental illness is present in incarcerated individuals at an estimated two to four times the rate found in the general population (Tala et al., 2017). Many correctional facilities in the U.S. are epicenters for infection and disease as well as health and mental health crises (Kinner et al., 2020; Tadros, Ribera, et al., 2020) because of a lack of investment in healthcare, overcrowding, unsanitary facilities, and limited access to services (Kinner et al., 2020). Although many incarcerated individuals are affected by mental illness, they often do not receive needed mental health treatment, with only one in six individuals in jail and one in three individuals in prison receiving treatment (Daniel, 2007). These needs can be addressed further using telehealth and TMH approaches.

Telehealth has been implemented in corrections facilities since the 1980s, although it has become more popular in the past decade as one way to improve access to care while saving money (The Pew Charitable Trust, 2010; Wheeler $\&$ Hinton, 2017). Few studies have examined TMH in corrections, including patient perspectives in receipt of TMH services. For instance, Magaletta et al. (2000) surveyed 75 individuals incarcerated in the federal prison system who had received TMH consultations. Patients reported overall satisfaction with TMH and increasing comfort levels over time, as well as a willingness to return for follow-up services. The primary challenge identified was when clients expressed anger and frustration, which may be more easily addressed in a face-to-face situation. Morgan et al. (2008) compared 186 incarcerated individuals who received TMH $(n=86)$ and face-to-face mental health $(n=100)$ services, they found that patients' perceptions of the work alliance, mood, and satisfaction with services did not differ.

\section{The Need for Relational TMH in Corrections}

Incarcerated individuals who have stable relationships with their families often have easier transitions out of prison in part because families provide a substantial amount of reentry support (McKay et al., 2019; Western, 2018). Relational mental health services can assist incarcerated individuals with strengthening family relationships to help their adjustment during incarceration and ease their transition back into the community during reentry (Arditti, 2012; Daniel, 2007; Gleeson et al., 2014; Swisher \& Waller, 2008). Relational therapy with incarcerated individuals and their loved ones may assist in improving communication, fostering connectedness, and enhancing positive relationship dynamics (Datchi et al., 2016; Gleeson et al., 2014; Tadros et al., 2019; 
Tadros \& Owens, 2020) and provide opportunities to learn and practice coping mechanisms and techniques such as increasing connection, communication skills, conflict resolution, validation, empathy, and acceptance (Tadros et al., 2019). Strong social ties have been known to protect individuals from mental health issues, and this is one reason why access to relational therapy in corrections facilities, where social support is minimal, is vital (Wallace et al., 2016). Unfortunately, however, relational TMH (as opposed to individual $\mathrm{TMH}$ ) services in corrections settings are extremely scarce.

Relational TMH appears to be scarce in corrections settings for a number of reasons, including cost, access to technology, stigma, availability of family-oriented programs and services, family conflict, and the coronavirus pandemic. In addition, mental health issues are often stigmatized, which can prevent individuals from seeking out such services, yet integrating TMH services with other health services in a collaborative way can help reduce stigma. Prisons and jails vary widely in their implementation of family-oriented programs, in contrast to individually oriented programs and services. For example, there are a growing number of parenting programs available in correctional facilities (Charles et al., 2020; McKay et al., 2019; Poehlmann-Tynan et al., 2020), and when integrated approaches are used, these programs could enhance the provision of mental health services. Family conflict is another barrier to implementation of relational $\mathrm{TMH}$. Ironically, the families who may benefit from such services may be the ones who are harder to reach, especially when partners and other family members are angry with or try to distance themselves from the incarcerated individual (Comfort et al., 2016). Addressing such conflicts is critical. Finally, restrictions related to the COVID-19 pandemic have limited or eliminated in-person visits to corrections facilities, further challenging family communication and increasing the need for TMH options.

During the COVID-19 pandemic, incarceration-of oneself or a loved one-is particularly stress-inducing because of the quick spread of the virus in congregate settings (Puglisi et al., 2021) and limited means of communication between incarcerated individuals and their families. The pandemic is increasing stress and conflict within families broadly, in addition to undermining relationship quality between romantic couples (Pietromonaco \& Overall, 2020). The challenges of the pandemic are likely to exacerbate preexisting external stressors such as incarceration (Pietromonaco \& Overall, 2020). In addition to grief because of elevated death rates during the pandemic, a different type of loss does not entail the death of a loved one. Instead, the loss consists of alterations to daily routines, missing out on events, and being physically distanced from others, all in the context of uncertainty (Arditti, 2012; Woods, 2020). This type of loss is considered to be a type of ambiguous loss
(Boss, 2009). Ambiguous loss can be compounded by the complexities of having a loved one incarcerated and being restricted from visiting (Arditti, 2012). An abundance of losses, including ambiguous loss and potential losses, during the COVID-19 pandemic has led to many people experiencing anxiety and other mental health symptoms (Lebow, 2020; Weingarten \& Worthen, 2018). Such losses related to COVID-19 are negatively linked to relationship quality and positively associated with conflict (Balzarini et al., 2020).

In addition to boosting an individual's personal coping skills, relational therapeutic services may help incarcerated individuals and their families explore the complex feelings of ambiguous loss in relationships during this time. Because perceived partner responsiveness can be a protective factor against pandemic-related stressors, building relationship quality and fostering resilience are essential (Balzarini et al., 2020). Family support has been found to be particularly important in facilitating resilience processes regarding the mental health of incarcerated parents with young children (Milavetz et al., 2020). Moreover, highlighting a couple or family's resilience during stressful times can aid clients in being more adaptable and open-minded (Woods, 2020).

\section{Recommendations}

It is vital that MFTs determine how to best deliver relationship-oriented clinical services to underserved populations that are often forgotten during crises, including those who are in corrections facilities. We recommend using TMH in corrections to increase access to care and build collaborative approaches to mental health and health care. We also discuss implementation challenges, the importance of ethics, and directions for future practice and research related to relational TMH in corrections. These recommendations are based on review of the literature and the authors' clinical and research experiences within correctional settings.

\section{Increase in Access to Care}

Remote delivery of therapy is beneficial because it can reach more incarcerated individuals and provide greater access to care, since incarceration facilities have a high turnover of mental health providers and transporting incarcerates to facilities has additional costs that limit visitation and therapeutic accessibility (Batastini et al., 2020). In addition, TMH allows the transition between stages of care to be more seamless, which increases the potential for continuity of care (Batastini et al., 2020). Due to the pandemic plaguing incarceration facilities, with relational $\mathrm{TMH}$, individuals considered higher risk for becoming ill because of coronavirus, due to age or being immunocompromised, can obtain the services needed without risking their physical 
health (Wheeler \& Hinton, 2017). TMH can connect justice involved families living in distant areas and/or in long-distance relationships (Wrape \& McGinn, 2019).

\section{Telehealth Cost}

Aside from the free or reduced cost phone calls or remote video visits provided by some corrections systems (Prison Policy Initiative, 2020), families may need to spend more money on expensive phone and video calls with incarcerated family members (Skora Horgan \& Poehlmann-Tynan, 2020). Several states have exclusive deals with phone service providers, and some may receive a percentage of profits (PerezFeliciano, 2020). Prisons contain telephone fees that do not exist in the outside world, for instance charging \$1-3 an hour and charging connection fees (Perez-Feliciano, 2020). It is common for these telephone fees to become a part of prison' budgets and ultimately families bear the cost (PerezFeliciano, 2020). TMH could help alleviate these communication barriers. Thus, it is also possible that prison administrators could continue to force costs of services on loved ones of incarcerated individuals. However, due to Covid-19 and the coinciding halt in in-person visitation, almost all states cancelled typical telephone fees to allow incarcerated individuals to call their loved ones (Dallaire et al., 2021). Further, these states that already had video accessibility also offered free video calls (Dallaire et al., 2021). It is vital to note, we are in support of continuing these offerings as well as lowering the costs for everyone involved post-pandemic.

During the pandemic, most corrections facilities have stopped in-person visits to decrease the spread of the virus, resulting in a reliance on phone calls or remote video visits, which can be expensive in corrections settings (Williams \& Ivory, 2020). The cost of video calls within correctional facilities are privatized and can be extremely expensive, especially in jails due to the lack of regulation (Wagner \& Jones, 2019). Furthermore, incarceration disproportionately affects families of lower socioeconomic backgrounds (Haskins et al., 2016), which could further impede reliable access to technology. Although cost and access to technology can be barriers, previous research has found cost savings for use of TMH.

Many incarcerated individuals come from families with lower income (Turney, 2014), and transportation costs are often a barrier when traveling to a prison or jail. Relational TMH eliminates transportation costs. This is convenient for therapists, too, as it eliminates their travel and safety concerns that may be pertinent due to COVID-19 (Deslich et al., 2013; Springer et al., 2020). TMH enables therapists, who are also social distancing and quarantining during the pandemic, to work from home while providing necessary services to vulnerable people. MFTs are now performing the majority of their practice online (Hertlein et al., 2021).
Telehealth has recently become more prevalent and health care systems are increasingly using accessible telecommunication tools such as Zoom, Skype, Webex, Microsoft Teams, Google Meets, and Facetime (Wang et al., 2020). Telehealth and managed care reimbursement policies have rapidly evolved to accommodate mental health services so people will not lose coverage for these services.

The cost of virtual therapy may be a concern for corrections, although relational TMH is becoming more affordable, and most prisons and jails are already equipped with computers (Bischoff, 2004) and internet access for staff. The cost of such telecommunication services can be offset by TMH platforms such as Brighter Vision, Simple Practice, Doxy. me and TheraNest, as they have provided free resources and continuing education webinars for therapists providing TMH services during the pandemic (Moring et. al., 2020). These are Health Insurance Portability and Accountability Act (HIPAA) compliant platforms that include waiting rooms, file sharing, and have a secure file feature (Moring et. al., 2020). Advantages of TMH approaches in corrections include the ability to serve those in rural locations, provision of typically unavailable specialty services, and serving more people because of the cost savings (Perle \& Nierenberg, 2013). Indeed, Deslich's (2013) review found that the use of TMH in corrections saved between $\$ 12,000$ to $\$ 1$ million per corrections system. The review did not focus on relational TMH in corrections, however.

\section{Collaborative Healthcare}

Collaborative healthcare in corrections settings can improve healthcare delivery and outcomes, including mental health services. Successful collaboration is contingent upon a number of factors, including the ability to connect with each other and the beliefs of the professionals involved (Kaur \& Tadros, 2019a; Tadros, 2019; Luetsch \& Rowett, 2016). While collaborating with each other, healthcare professionals should leverage their strengths by utilizing their unique skills from treatment planning, to service delivery, to coordination of care (Doherty et al., 2014; Kaur \& Tadros, 2019a; Tadros, 2019; Marlowe et al., 2012). In correctional settings, TMH services can be collaborative in various ways, improving access and delivery (Kaur \& Tadros, 2019a; Tadros, 2019). Treatment team meetings can be conducted via telehealth platforms that can host multiple professionals and patients without risk for infection or disease spread. Telehealth approaches can also bring together specialty service providers.

In addition, correctional collaborative healthcare can be conceptualized through a health justice lens, focusing on the social determinants of health, battling cultural biases, and promoting health at large (Wiley, 2014). A health justice approach coincides with the provision of healthcare during 
the COVID-19 crisis (Wiley, 2014) and can be beneficial when applying telehealth and TMH services collaboratively in corrections. During COVID-19, people of color are doubly disadvantaged because of health disparities related to the coronavirus and structural inequities in systems of care especially in African American communities (Kullar et al., 2020). Similarly, incarcerated people of color and their families experience heightened negative effects of the virus. It must be a priority to achieve health justice and insist on the elimination of health inequities and social injustices (Benfer, 2015). Blatantly ignoring injustices in low-income communities results in poor health outcomes, impacting society as a whole (Benfer, 2015). TMH services extend this treatment to vulnerable individuals and families.

\section{Special Considerations for Implementing Relational TMH in Corrections}

Couples and families experience great stress during incarceration, with $40 \%$ of marriages resulting in divorce (Doss et al., 2017; Whisman et al., 2008). These increased levels of stress are hypothesized to be amplified with stay-at-home orders and social distancing policies in place. Further, stress and other related consequences of incarceration previously discussed may be additionally compounded during this unique time. Although it is common for therapists to assist people in their life transitions, many therapists were unprepared for changes to services required by the pandemic. To meet the mental health needs of vulnerable populations, such as those affected by corrections, it is imperative that therapists seek out assistance from professional associations, supervisors, and others to be able to provide proper care. Therapists are advised to seek out training and resources to assist during this transitional time from organizations such as, but not limited to, the National Board for Certified Counselors, AAMFT, and PESI for telehealth or relational TMH generally. Still, resources must also be developed for treating special populations such as those involved in the criminal justice system. We suggest utilizing guidelines from the National Commission on Correctional Health Care to attempt to bridge that gap until specific training for relational TMH is created for correctional settings in addition to the recommendations set forth in this article.

Therapists are recommended to help clients understand what TMH looks like, because it may be an unfamiliar concept to many. Some people may operate under the assumption that treatment will be less effective when conducted online or that treatment will be less personal. Therapists can validate these concerns and discuss ways to mitigate them. Additionally, therapists are advised to become as comfortable as possible with the utilization of TMH, not only for clients to emulate that comfort, but so that they can keep up with the various changes made to distance protocols and procedures to ensure the best client care. Similarly, rules and regulations in corrections facilities are ever changing and thus, therapists working in such environments must be mindful of changing protocols as well as confidentiality.

Families of incarcerated individuals may lack internet access. This can be addressed by low-income internet programs offered by internet providers, school districts, and the federal government (Cossick, 2020). TMH increases access to care with its convenience and allows for relational therapy that is so desperately needed by incarcerated individuals and their families. Most connected individuals living in 2020 experience occasional technology issues such as connectivity and lack of user comfort or familiarity. It is vital to normalize this with clients and explain that this may happen when conducting therapy online. A strong internet connection is needed, but prison servers are not always reliable (Deslich et al., 2013). A proficient group of information technology staff is needed to assist with there being a higher likelihood of technology issues arising. The proper placement of video conferencing is important to practitioners as it allows for visual identification and the observation of body language (Deslich et al., 2013).

While in the convenience of a closed door or an office, therapists can ensure that the privacy of their clients stays between office walls. However, when clients utilize telehealth platforms, it may be difficult to determine location in corrections settings. Therapists are advised to always ask where the clients are to ensure safety as well as privacy. Unfortunately, there is a lack of privacy in most carceral settings, but individuals who are incarcerated for nonviolent crimes can often communicate with their therapist without a correctional officer present, depending on the policies of the facility (Deslich et al., 2013). If a therapist is physically at a correctional facility with an incarcerated individual and a telehealth platform is being used with a family member, a therapist may have limited control over the environment for family members. Regardless of the situation, asking all parties if they have privacy is critical so that particular topics are not discussed if the clients deem it uncomfortable to do so. It is a therapist's job to do their best to protect confidentiality as much as possible even if they are not in full control of the environment. Additionally, there may be regulations within correctional settings on internet monitoring, this seems to be specific to each particular facility. Understandably, there may be concerns over whether the internet is being monitored and what level of confidentiality the incarcerated individual and/or families have. These questions should not be left unanswered during treatment. A case study discussed this exact issue being present in a private prison, they added limits to therapist confidentiality (Tadros \& Finney, 2019). The limits consisted of breaking rules of the facility, therefore, this may negatively impact the therapeutic alliance (Tadros \& Finney, 2019). We advise 
therapists to inquire about these procedures prior and have them clearly stated in the informed consent prior to beginning therapy.

In addition to these types of special considerations of potentially disruptive correctional control, there is likely already the present mistrust from client to therapist due to setting. A strong therapeutic alliance coincides with client's trust and potential ability to change (Escudero et al., 2011). Developing this alliance and earning trust is considered a unique challenge of therapists joining with incarcerated individuals and their families as oftentimes therapists are viewed as being a part of the system that oppresses them (Tadros, Ribera, et al., 2020), and this can be a challenge to overcome especially in initial stages of therapy. When you pair this with the challenges of joining with clients over TMH, this may be an even bigger challenge. Thus, we recommend prior works that have suggested embodying an empathetic, yet curious stance where the therapist attempts to understand the client(s) intersectionality, through their social location and context (Tadros \& Finney, 2018). Further, we advise therapists to be patient in earning this trust rather than expecting it from individuals that have likely been consistently oppressed and stigmatized in various forms.

\section{Ethical Considerations}

The code of ethics for the American Association of Marriage and Family Therapy (AAMFT) touches on ethics, and state licensing boards cover state regulations (AAMFT, 2015). Technology use is on the rise for mental health professionals, yet, prior to the COVID-19 pandemic, a clear and comprehensive ethical and legal guide on technology use in therapy was missing (Pennington et al., 2017). Research on the ethical and legal guides for technology use in MFT examined state laws and regulations regarding MFT licensure and found that there was minimal mention of technology, and seven states had no mention of technology at all (Pennington et al., 2017). MFTs are behind in comparison to other mental health professionals when it comes to cross-state certifications, which are often needed when clients move (Caldwell et al., 2017). Further, clients being physically separated from one another may cause additional barriers to treatment such as not being able to see them due to state licensure regulations as well as connectivity issues. Another challenge involves new technologies emerging before regulations can be made for them (Caldwell et al., 2017).

In response to the COVID-19 pandemic, it is particularly important that MFTs adhere to their code of ethics and state regulations when administering TMH services. Unfortunately, as convenient and cost-effective as TMH services are, there are still various barriers to implementation within the criminal justice system. Although incarcerated individuals in the U.S. have a constitutional right to receive mental health care and treatment in prisons, research shows that treatment is not common (Daquin \& Daigle, 2018; Reingle \& Connell, 2014). The method of treatment that incarcerated individuals receive also varies by state, which can create barriers to access in some states (Daquin \& Daigle, 2018).

The AAMFT code of ethics provides information regarding adherence to state or province laws, confidentiality, technology training, and proper documentation (AAMFT, 2015). Section 1.2 of the code of ethics explains informed consent and the importance of client comprehension (AAMFT, 2015). As incarcerated individuals may have literacy challenges, informed consent should be an ongoing process for them and their families to ensure comprehension (Barnett \& Kolmes, 2016). An addition was made to the HIPAA in 2013 that includes protection for patient data with new technology used such as video teleconferencing, internet, and mobile phone apps (Kramer et al., 2015). Section 6.2 in the AAMFT code of ethics mentions risks associated with technology assisted service as there is an increased risk to confidentiality with electronic communication, which would need to be stressed to incarcerated individuals and their families (AAMFT, 2015; Barnett \& Kolmes, 2016).

All MFTs are required to use HIPAA compliant software to avoid security concerns. MFTs are gatekeepers of information with expectations of upholding confidentiality with the exception of their duty to warn (Caldwell, 2016; Tadros, 2020; Tadros, Fye, et al., 2020; Tadros, Ribera, et al., 2020). Incarcerated individuals are part of a protected population, therefore, it is paramount that with TMH services, MFTs are cautious of security breaches that may be more difficult to manage due to correctional facility procedures in place, such as multiple employees in the facility potentially having access to client files. The use of electronic health records (EHRs) has allowed for higher security and for faster dissemination of records across medical staff in prisons (Deslich et al., 2013). Some examples of HIPAA secure TMH platforms that house electronic health records are Brighter Vision, Simple Practice, TheraNest, CPH \& Associates (Fava, 2020). Further, practitioners must assure that clients are able to maneuver the software needed for therapy sessions, which requires support from prison administration, which has not always been provided (Deslich et al., 2013; Kramer et al., 2015). These issues must be considered when implementing TMH in corrections facilities. MFTs are advised to consult with their clinical supervisor(s) if they have any ethical concerns or questions, similarly, supervisors are encouraged to discuss issues with their supervising mentors to ensure best ethical practices are utilized (Tadros, 2020; Tadros, Fye, et al., 2020; Tadros, Ribera, et al., 2020). 


\section{Future Directions for Practice and Research}

There are a number of areas to explore in future practice and research, including issues related to insurance reimbursement, training and employment of MFTs, development of best practices, and development of an evidence base for use of TMH in corrections systems. We recommend five TMH advancements that can further its usage, including: (1) Advocating passage of legislation that would make insurance companies continue TMH coverage even after COVID-19, as well as TMH payment parity, which would allow MFTs to reach a larger proportion of underserved individuals; (2) Facilitating the graduate training-via coursework and clinical experiences - of MFTs in working with incarcerated individuals, especially in treating relational concerns; (3) Increasing the number of MFTs employed in the criminal justice system, as currently this is rare (Datchi et al., 2016; Tadros \& Finney, 2018, 2019; Tadros, Schleiden, et al., 2020), but it would allow for more adequate relational therapeutic services that could be used regularly instead of just during times of crisis (Smith et al., 2020); (4) Incorporating collaboration between professionals on best practices for relational TMH in corrections settings, including the creation of recommendations and guidelines for providing optimal client care, and (5) Creating policies for practice that are sensitive to the fact that social distancing is a privilege that incarcerated people do not have.

Family therapy has been shown to reduce recidivism in earlier works. Alexander and Parsons (1973) examined short-term behavioral intervention programs for justiceinvolved families and found that these participants were less likely to recidivate as a result of this family oriented program. More recent research has shown that family therapy has aided in positive familial interactions (Tadros \& Finney, 2018, 2019). Thus, creating more opportunities for family therapy to occur through TMH may increase availability for care to further decrease recidivism rates. In addition to clinical practice advancements, researchers must also evaluate the practices used in relational TMH services, along with client outcomes (e.g., symptom reduction and improved family relationships), so that evidence-based services are ensured, as corrections systems typically seek out evidence-based approaches. Such research will help MFTs engage in ethical evidence-based practices when using technologies that are quickly growing and changing (Pennington et al., 2017). Additionally, future research should determine methods of connecting families who lack access to necessary technology or who are not technologically literate (Lebow, 2020), which is common when a family member is incarcerated because of economic disparities in criminal justice involvement. Future work should also study the self-selection process among clients in the criminal justice system and how reasons for participation differ between family members who are incarcerated versus those who are not.

Although studies note that technology can actually engage with more diverse families than in-person services, it is still crucial to increase accessibility across a wide range of families (Doss et al., 2017). Professional associations, including the American Counseling Association, are incorporating ethics statements that require counselors to work towards decreasing barriers to access for telehealth services (Teufel-Prida et al., 2018). Additionally, research has identified frameworks that enable successful implementation of telehealth services in the community, including the integration of technology into existing structures with institutional support, reimbursements of TMH, and the creation of user-friendly technical platforms (Van Dyk, 2014). Other telehealth pilot programs developed specific protocols for troubleshooting different technological issues once clients have devices, which enables the mental health counselor to provide technical support on issues related to connection speed and delayed or dysfunctional audio and video (Lee et al., 2015). Lastly, there is no research available on the actual distribution of telehealth materials to incarcerated individuals; therefore, we call for future examination and recommendation for implementation.

A post-COVID-19 world calls for innovative methods of thought and implementation within different domains of mental health delivery (Nissen, 2020). The pandemic will end, but the need for relational mental health care in corrections, where families are separated and not able to see each other will continue. It has been recommended for MFTs to be flexible and adaptable to clients' needs (Tadros, 2019), this should apply not only theoretically, but how treatment is being conducted logistically as well. In sum, we advocate for incarcerated individuals and their families to have access to TMH services, including why this is important and how relational TMH can be implemented. However, much more work needs to be done to allow for telehealth to be the norm versus an emergency alternative. The hope is that what began as a response to the pandemic can also contribute to the normalization and destigmatization of engaging in mental health services in corrections and with families in the community.

\section{References}

Alexander, J. F., \& Parsons, B. V. (1973). Short-term behavioral intervention with delinquent families: Impact on family process and recidivism. Journal of Abnormal Psychology, 81(3), 219-225. https://doi.org/10.1037/h0034537

Ammar, A., Chtourou, H., Boukhris, O., \& Hökelmann, A. (2020). Social participation and life satisfaction of peoples during the COVID-19 home confinement: the ECLB-COVID19 multicenter 
study. Public Health. https://doi.org/10.1101/2020.05.05.20091 066

American Association for Marriage and Family Therapy. (2015). Code of ethics. https://www.aamft.org/imis15/Documents/Legal\% 20Ethics/Board\%20Approved\%20Code $\% 20$ for $\% 20$ Web $\% 20$ Sec ured.pdf.

Arditti, J. A. (2012). The effects of incarceration on families and children. Parental incarceration and the family: Psychological and social effects of imprisonment on children, parents, and caregivers. New York: New York University Press.

Arditti, J., \& Savla, J. (2015). Parental incarceration and child trauma symptoms in single caregiver homes. Journal of Child \& Family Studies, 24(3), 551-561. https://doi.org/10.1007/ s10826-013-9867-2

Balzarini, R. N., Muise, A., Zoppolat, G., Di Bartolomeo, A., Rodrigues, D. L., Alonso-Ferres, M., Urganci, B., Debrot, A., Pichayayothin, N. B., Dharma, C., Chi, P., Karremans, J., Schoebi, D., Slatcher R. (2020, May 16). Love in the time of covid: Perceived partner responsiveness buffers people from lower relationship quality associated with covid-related stressors. Journal of Consulting and Clinical Psychology. https://doi.org/10.31234/ osf.io/e $3 \mathrm{fh} 4$.

Barnett, J. E., \& Kolmes, K. (2016). The practice of tele-mental health: Ethical, legal, and clinical issues for practitioners. Practice Innovations, 1(1), 53-66. https://doi.org/10.1037/pri0000014

Batastini, A. B., Jones, A. C. T., Lester, M. E., \& Davis, R. M. (2020). Initiation of a multidisciplinary telemental health clinic for rural justice-involved populations: Rationale, recommendations, and lessons learned. Journal of Community Psychology, 48(7), 21562173. https://doi.org/10.1002/jcop.22424

Benfer, E. A. (2015). Health justice: A framework (and call to action) for the elimination of health inequity and social injustice. The American University Law Review, 65(2), 275-351

Bischoff, R. J., Hollist, C. S., \& Smith, C. W. (2004). Addressing the mental health needs of the rural underserved: Findings from a multiple case study of a behavioral telehealth project. Contemporary Family Therapy, 26, 179-198. https://doi.org/10.1023/B: COFT.0000031242.83259.fa

Boss, P. (2009). Ambiguous loss: Learning to live with unresolved grief. Cambridge: Harvard University Press.

Caldwell, B. E. (2016). Ethics and supervision. In K. Jordan (Ed.), Couple, marriage, and family therapy supervision (pp. 151-168). SpringerPublishing Company.

Caldwell, B. E., Bischoff, R. J., Derrig-Palumbo, K. A., \& Liebert, J. D. (2017, February 17). Best practices in the online practice of couple and family therapy. https://www.aamft.org/Documents/ Products/AAMFT_Best_Practices_for_Online_MFT.pdf.

Charles, P., Kerr, M., Wirth, J., Jensen, S., Massoglia, M., \& Poehlmann-Tynan, J. (2020). Lessons from the field: Developing and implementing an intervention for jailed parents and their children. Family Relations, 70(1), 8

Comer, J. S., Furr, J. M., Miguel, E. M., Cooper-Vince, C. E., Carpenter, A. L., Elkins, R. M., Kerns, C. E., Cornacchio, D., Chou, T., Coxe, S., DeSerisy, M., Sanchez, A. L., Golik, A., Martin, J., Myers, K. M., \& Chase, R. (2017). Remotely delivering realtime parent training to the home: An initial randomized trial of Internet-delivered parent-child interaction therapy (I-PCIT). Journal of Consulting and Clinical Psychology, 85(9), 909-917. https://doi.org/10.1037/ccp0000230

Comfort, M., McKay, T., Landwehr, J., Kennedy, E., Lindquist, C., \& Bir, A. (2016). The costs of incarceration for families of prisoners. International Review of the Red Cross, 98(903), 783-798. https://doi.org/10.1017/S1816383117000704

Coronavirus disease (COVID-19) Pandemic. (n.d.). https://www.who. int/emergencies/diseases/novel-coronavirus-2019?gclid=Cj0KC
Qjw2PP1BRCiARIsAEqv-pR6W-UVD0S_0cAm0-Uyb3N 1ApeXjnT274DQkpfmquXHqKiS48o-zv8aAtBREALw_wcB.

Cossick, S. (2020, May 14). Low income internet guide: Find discount internet service in your area. https://www.allconnect.com/blog/ low-income-internet-guide.

Dallaire, D. H., Shlafer, R. J., Goshin, L. S., Hollihan, A., PoehlmannTynan, J., Eddy, J. M., \& Adalist-Estrin, A. (2021). COVID-19 and prison policies related to communication with family members. Psychology, Public Policy, and Law. https://doi.org/10. 1037/law0000297

Daniel, A. E. (2007). Care of the mentally ill in prisons: Challenges and solutions. Journal of American Academic Psychiatry Law, $35,406-410$

Daquin, J. C., \& Daigle, L. E. (2018). Mental disorder and victimisation in prison: Examining the role of mental health treatment. Criminal Behaviour \& Mental Health, 28(2), 141-151. https:// doi.org/10.1002/cbm.2056

Datchi, C., Barretti, L., \& Thompson, C. (2016). Family services in adult detention centers: Systemic principles for prisoner reentry. Couple and Family Psychology, 5(2), 89-104. https://doi.org/10. 1037/cfp0000057

Datchi, C. C., \& Sexton, T. L. (2013). Can family therapy have an effect on adult criminal conduct? Initial evaluation of functional family therapy. Couple and Family Psychology: Research and Practice, 2, 278-293

Dausch, B. M., Miklowitz, D. J., Nagamoto, H. T., Adler, L. E., \& Shore, J. H. (2009). Family-focused therapy via videoconferencing. Journal of Telemedicine and Telecare, 15(4), 211-214

DeHart, D., Shapiro, C., \& Clone, S. (2018). "The Pill Line Is Longer Than the Chow Line": The impact of incarceration on prisoners and their families. Prison Journal, 98(2), 188-212. https://doi. org/10.1177/0032885517753159

Deslich, S. A., Thistlethwaite, T., \& Coustasse, A. (2013). Telepsychiatry in correctional facilities: Using technology to improve access and decrease costs of mental health care in underserved populations. The Permanente Journal, 17(3), 80-86. https://doi. org/10.7812/TPP/12-123

Doherty, W. J., McDaniel, S. H., \& Hepworth, J. (2014). Contributions of medical family therapy to the changing health care system. Family Process, 53(3), 529-543.

Doss, B. D., Feinberg, L. K., Rothman, K., Roddy, M. K., \& Comer, J. S. (2017). Using technology to enhance and expand interventions for couples and families: Conceptual and methodological considerations. Journal of Family Psychology, 31(8), 983-993. https://doi.org/10.1037/fam0000349

Escudero, V., Friedlander, M. L., \& Heatherington, L. (2011). Using the e-SOFTA for video training and research on alliance-related behavior. Psychotherapy, 48, 138-147. https://doi.org/10.1037/ a0022188

Fava, G. A. (2020). The decline of pluralism in medicine: Dissent is welcome. Psychotherapy and Psychosomatics, 89(1), 1-5. https://doi.org/10.1159/000505085

Gassova, Z., \& Werner-Wilson, R. J. (2018). Characteristics of e-therapy websites involving marriage and family therapists. American Journal of Family Therapy, 46(1), 27-43. https://doi.org/10. 1080/01926187.2018.1428127

Gleeson, J. P., Bonecutter, F. J., \& Cryer-Coupet, Q. (2014, September 17). Building and restoring coparenting relationships with mothers in jail and kin caring for their children: Results of a pilot study. CWLA National Kinship Care Conference: Building Communities of Caring for Children and Families. http://www. cwla.org/wp-content/uploads/2014/12/KinConf-A2.pdf.

Gueta, K. (2018). The experience of prisoners' parents: A meta-synthesis of qualitative studies. Family Process, 57(3), 767-782. 
Hairston, C. F. (1991). Family ties during imprisonment: Important to whom and for what? The Journal of Sociology \& Social Welfare, $18(1), 6$

Haskins, A. (2014). Unintended consequences: Effects of paternal incarceration on child school readiness and later special education placement. Sociological Science, 1, 141-158

Haskins, A. R. (2015). Paternal incarceration and child-reported behavioral functioning at age 9. Social Science Research, 52, 18-33. https://doi.org/10.1016/j.ssresearch.2015.01.001

Haskins, A. R. (2016). Beyond boys' bad behavior: Paternal incarceration and cognitive development in middle childhood. Social Forces, 95(2), 861-892. https://doi.org/10.1093/sf/sow066

Hawks, L., Woolhandler, S., \& McCormick, D. (2020). COVID-19 in prisons and jails in the United States. JAMA Internal Medicine., 180, 1041-1042

Hertlein, K., Blumer, M., \& Smith, J. (2014). Marriage and family therapists' use and comfort with online communication with clients. Contemporary Family Therapy, 36(1), 58-69. https://doi. org/10.1007/s10591-013-9284-0

Hertlein, K. M., Drude, K. P., Hilty, D. M., \& Maheu, M. M. (2021). Toward proficiency in telebehavioral health: Applying interprofessional competencies in couple and family therapy. Journal of Marital and Family Therapy. https://doi.org/10.1111/jmft.12496

Hill, J. V., Allman, L. R., \& Ditzler, T. F. (2001). Utility of real-time video teleconferencing in conducting family mental health sessions: Two case reports. Telemedicine Journal and E-Health, $7(1), 55-59$

Kaur, L., \& Tadros, E. (2019). The benefits of interprofessional collaboration for a pharmacist and family therapist. The American Journal of Family Therapy. https://doi.org/10.1080/01926187. 2018.1563003

Kinner, S. A., Young, J. T., Snow, K., Southalan, L., Lopez-Acuña, D., Ferreira-Borges, C., \& O'Moore, É. (2020). Prisons and custodial settings are part of a comprehensive response to COVID-19. The Lancet Public Health, 5(4), e188-e189. https://doi.org/10. 1016/S2468-2667(20)30058-X

Kullar, R., Marcelin, J. R., Swartz, T. H., Piggott, D. A., Macias Gil, R., Mathew, T. A., \& Tan, T. (2020). Racial disparity of coronavirus disease 2019 in African American Communities. The Journal of Infectious Diseases, 222(6), 890-893

Kramer, G. M., Kinn, J. T., \& Mishkind, M. C. (2015). Legal, regulatory, and risk management issues in the use of technology to deliver mental health care. Cognitive and Behavioral Practice, 22(3), 258-268. https://doi.org/10.1016/j.cbpra.2014.04.008.

Lebow, J. L. (2020). Family in the age of COVID-19. Family Process. https://doi.org/10.1111/famp.12543

Lee, J. F., Schieltz, K. M., Suess, A. N., Wacker, D. P., Romani, P. W., Lindgren, S. D., Kopelman, T. G., \& Dalmau, Y. C. P. (2015). Guidelines for developing telehealth services and troubleshooting problems with telehealth technology when coaching parents to conduct functional analyses and functional communication training in their homes. Behavior Analysis in Practice, 8(2), 190-200. https://doi.org/10.1007/s40617-014-0031-2

Luetsch, K., \& Rowett, D. (2016). Developing interprofessional communication skills for pharmacists to improve their ability to collaborate with other professions. Journal of Interprofessional Care, 30(4), 458-465. https://doi.org/10.3109/13561820.2016. 1154021

Magaletta, P. R., Fagan, T. J., \& Peyrot, M. F. (2000). Telehealth in the Federal Bureau of Prisons: Inmates' perceptions. Professional Psychology: Research and Practice, 31(5), 497-502. https://doi. org/10.1037/0735-7028.31.5.497

Marlowe, D., Hodgson, J., Lamson, A., White, M., \& Irons, T. (2012). Medical family therapy in a primary care setting: A framework for integration. Contemporary Family Therapy, 34, 244-258. https://doi.org/10.1007/s10591-012-9195-5
McKay, T., Comfort, M., Lindquist, C., \& Bir, A. (2019). Holding on: Family and fatherhood during incarceration and reentry. University of California Press. https://doi.org/10.1525/9780520973312

Milavetz, Z., Pritzl, K., Muentner, L., \& Poehlmann-Tynan, J. (2020). Unmet mental health needs of jailed parents with young children. Family Relations. https://doi.org/10.1111/fare.12525

Miller, J. M., \& Blumstein, A. (2020). Crime, justice \& the COVID-19 pandemic: Toward a national research agenda. American Journal of Criminal Justice, 45(4), 515-524. https://doi.org/10.1007/ s12103-020-09555-z

Mitchell, M. M., Spooner, K., Jia, D., \& Zhang, Y. (2016). The effect of prison visitation on reentry success: A meta-analysis. Journal of Criminal Justice, 47, 74-83. https://doi.org/10.1016/j.jcrim jus.2016.07.006

Morgan, R. D., Patrick, A. R., \& Magaletta, P. R. (2008). Does the use of telemental health alter the treatment experience? Inmates' perceptions of telemental health versus face-to-face treatment modalities. Journal of Consulting and Clinical Psychology, 76, 158-162. https://doi.org/10.1037/0022-006X.76.1.158

Moring, J. C., Dondanville, K. A., Fina, B. A., Hassija, C., Chard, K., Monson, C., LoSavio, S. T., Wells, S. Y., Morland, L. A., Kaysen, D., Galovski, T. E., \& Resick, P. A. (2020). Cognitive processing therapy for posttraumatic stress disorder via telehealth: Practical considerations during the COVID-19 pandemic. Journal of Traumatic Stress, 33(4), 371-379. https://doi.org/10.1002/jts.22544

Murphey, D., \& Cooper, P. M. (2015). Parents behind bars: What happens to their children? Child Trends.

Nissen, L. (2020). Social work and the future in a post-Covid 19 world: A foresight lens and a call to action for the profession. Journal of Technology in Human Services, 38(4), 309-330. https://doi. org/10.1080/15228835.2020.1796892

Pennington, M., Patton, R., Ray, A., \& Katafiasz, H. (2017). A brief report on the ethical and legal guides for technology use in marriage and family therapy. Journal of Marital \& Family Therapy, 43(4), 733-742. https://doi.org/10.1111/jmft.12232

Perez-Feliciano, L., Adams, M., \& Nayer, G. (2020). Returning inmates and their families: Public policy issues for successful prisoner reentry. Journal of Administrative Sciences and Policy Studies. https://doi.org/10.15640/jasps.v8n2a1.

Perle, J., \& Nierenberg, B. (2013). How psychological telehealth can alleviate society's mental health burden: A literature review. Journal of Technology in Human Services, 31(1), 22-41. https:// doi.org/10.1080/15228835.2012.760332

Peterman, A., Potts, A., O’Donnell, M., Thompson, K., Shah, N., Oertelt-Prigione, S., \& van Gelder, N. (2020). Pandemics and violence against women and children. Center for Global Development working paper, 528.

Pietromonaco, P. R., \& Overall, N. C. (2020). Applying relationship science to evaluate how the COVID-19 pandemic may impact couples' relationships. American Psychologist. https://doi.org/ 10.1037/amp0000714

Poehlmann-Tynan, J., Cuthrell, H., Weymouth, L., Burnson, C., Frerks, L., Muentner, L., Holder, N., Milavetz, Z., Lauter, L., Hindt, L., Davis, L., Schubert, E., \& Shlafer, R. (2020). Multisite randomized efficacy trial of educational materials for young children with incarcerated parents. Development and Psychopathology. https://doi.org/10.1017/S0954579419001792

Prison Policy Initiative. (August 18, 2020). Responses to the COVID19 pandemic. https://www.prisonpolicy.org/virus/virusresponse. html\#paroleprobation.

Puglisi, L. B., Malloy, G. S. P., Harvey, T. D., Brandeau, M. L., \& Wang, E. A. (2021). Estimation of COVID-19 basic reproduction ratio in a large urban jail in the United States. Annals of Epidemiology, 53, 103-105. https://doi.org/10.1016/j.annepidem. 2020.09.002 
Reingle Gonzalez, J. M., \& Connell, N. M. (2014). Mental health of prisoners: Identifying barriers to mental health treatment and medication continuity. American Journal of Public Health, 104(12), 2328-2333. https://doi.org/10.2105/AJPH.2014.302043

Riad, A., Huang, Y., Zheng, L., \& Elavsky, S. (2020). COVID-19 induced anxiety and protective behaviors during COVID-19 outbreak: Scale development and validation. medRxiv. https:// doi.org/10.1101/2020.05.05.20050419

Sawyer, W., \& Wagner, P. (2020). Mass incarceration: The whole pie 2020. Prison Policy Initiative.

Simpson, A. T., Doarn, C. R., \& Garber, S. J. (2013, August). A Brief History of NASA's Contributions to Telemedicine. https://histo ry.nasa.gov/NASAtelemedicine-briefhistory.pdf.

Skora Horgan, E., \& Poehlmann-Tynan, J. (2020). In-home video chat for young children and their incarcerated parents. Journal of Children and Media. https://doi.org/10.1080/17482798.2020. 1792082

Smith, A. C., Thomas, E., Snoswell, C. L., Haydon, H., Mehrotra, A., Clemensen, J., \& Caffery, L. J. (2020). Telehealth for global emergencies: Implications for coronavirus disease 2019 (COVID-19). Journal of Telemedicine and Telecare. https://doi. org/10.1177/1357633X20916567

Springer, P., Bischoff, R. J., Kohel, K., Taylor, N. C., \& Farero, A. (2020). Collaborative care at a distance: Student therapists' experiences of learning and delivering relationally focused telemental health. Journal of Marital \& Family Therapy, 46(2), 201-217. https://doi.org/10.1111/jmft.12431y

Srikanth, A. (2020, April 28). Jails and prisons are some of the biggest coronavirus hotspots in the country. The Hill. https:// thehill.com/changing-america/respect/equality/495039-jailsand-prisons-are-some-of-the-biggest-coronavirus.

Stark, A. M., White, A. E., Rotter, N. S., \& Basu, A. (2020). Shifting from survival to supporting resilience in children and families in the COVID-19 pandemic: Lessons for informing US mental health priorities. Theory, Research, Practice, and Policy.

Swisher, R. R., \& Waller, M. R. (2008). Confining fatherhood: Incarceration and paternal involvement among nonresident White, African American, and Latino Fathers. Journal of Family Issues, 29(8), 1067-1088. https://doi.org/10.1177/0192513X08 316273

Tadros, E. (2020). Hierarchical privilege and power in supervision. Journal of Family Psychotherapy. https://doi.org/10.1080/ 08975353.2020.1809917

Tadros, E. (2019). The Tadros theory of change: An integrated structural, narrative, and solution-focused approach. Contemporary Family Therapy: An International Journal, 41(4), 347-356. https://doi.org/10.1007/s10591-019-09502-z

Tadros, E., \& Finney, N. (2019). Exploring the utilization of structural and medical family therapy with an incarcerated mother living with HIV. International Journal of Offender Therapy and Comparative Criminology. https://doi.org/10.1177/03066 $24 \mathrm{X} 18821825$

Tadros, E., \& Finney, N. (2018). Structural family therapy with incarcerated families. Family Journal, 26(2), 253-261. https:// doi.org/10.1177/1066480718777409

Tadros, E., Fye, J. M., McCrone, C. L., \& Finney, N. (2019). Incorporating multicultural couple and family therapy into incarcerated settings. International Journal of Offender Therapy \& Comparative Criminology, 63(4), 641-658

Tadros, E., Fye, J., \& Ray, A. (2020). The lived experience of sisters with an incarcerated brother: A phenomenological study. International Journal of Offender Therapy \& Comparative Criminology, 64(4), 335-354. https://doi.org/10.1177/03066 24X19877598

Tadros, E., Hutcherson, R., \& Greene, A. (2021). Advocating for an incarcerated informed lens in therapy. International Journal of
Offender Therapy and Comparative Criminology. https://doi. org/10.1177/0306624X20975162

Tadros, E., \& Ogden, T. E. (2020). Conceptualizing incarcerated coparenting through a structural family theory lens. Marriage \& Family Review, 56(6), 535-552

Tadros, E. \& Owens, D. (2020). Clinical implications for culturally informed counseling with incarcerated individuals. American Journal of Family Therapy.https://doi.org/10.1080/01926187. 2020.1813659.

Tadros, E., Ribera, E., Campbell, O., Kish, H., \& Ogden, T. E. (2020). A call for mental health treatment in incarcerated settings with transgender individuals. American Journal of Family Therapy. https://doi.org/10.1080/01926187.2020.1761273

Tadros, E., Schleiden, C., Jenkins, L., \& Aguirre, N. (2020). The experiences of marriage and family therapists working in incarcerated settings. American Journal of Family Therapy. https:// doi.org/10.1080/01926187.2020.1834469

Tala, A., Linda, R., Sieleni, B., Deol, H., \& Wallace, R. B. (2017). Inside the nation's largest mental health institution: A prevalence study in a state prison system. BMC Public Health. https://doi.org/10.1186/s12889-017-4257-0

Teufel-Prida, L. A., Raglin, M., Long, S. C., \& Wirick, D. M. (2018). Technology-assisted counseling for couples and families. The Family Journal, 26(2), 134-142. https://doi.org/10.1177/10664 80718770152

The Marshall Project. (2021). Our reporting on coronavirus. The Marshall Project. https://www.themarshallproject.org/2020/05/01/astate-by-state-look-at-coronavirus-in-prisons.

The Pew Charitable Trusts. (2010). Collateral costs: Incarceration's effect on economic mobility. Author.

Turney, K. (2014). The intergenerational consequences of mass incarceration: Implications for children's co-residence and contact with grandparents. Social Forces, 93(1), 299-327

Turney, K., \& Haskins, A. R. (2014). Falling behind? Children's early grade retention after paternal incarceration. Sociology of Education, 87(4), 241-258. https://doi.org/10.1177/0038040714 547086

Van Dyk, L. (2014). A review of tTelehealth service implementation frameworks. International Journal of Environmental Research and Public Health, 11(2), 1279-1298. https://doi.org/10.3390/ ijerph110201279

van Gelder, N. V., Peterman, A., Potts, A., Odonnell, M., Thompson, K., Shah, N., \& Oertelt-Prigione, S. (2020). COVID-19: Reducing the risk of infection might increase the risk of intimate partner violence. E Clinical Medicine, 21, 100348. https://doi.org/ 10.1016/j.eclinm.2020.100348

Wagner, P., \& Jones, A. (2019). State of phone justice: Local jails, state prisons and private phone providers. Prison Policy Initiative. https://www.prisonpolicy.org/phones/state_of_phone_justi ce.html.

Wallace, D., Fahmy, C., Cotton, L., Jimmons, C., McKay, R., Stoffer, S., \& Syed, S. (2016). Examining the role of familial support during prison and after release on post-incarceration mental health. International Journal of Offender Therapy \& Comparative Criminology, 60(1), 3-20. https://doi.org/10.1177/03066 24X14548023

Wang, C. J., Liu, T. T., Car, J., \& Zuckerman, B. (2020). Design, adoption, implementation, scalability, and sustainability of telehealth pograms. Pediatrics Clinic North America, 67(4), 675-682. https://doi.org/10.1016/j.pcl.2020.04.011

Weingarten, K., \& Worthen, M. (2018). The solace of an uncertain future: Acute illness, the self, and self-care. Family Process, 57(2), 572-586.

Western, B. (2018). Homeward: Life in the year after prison. New York: Russell Sage Foundation. 
Wheeler, J., \& Hinton, E. (2017). The effectiveness of telehealth on correctional facility healthcare: A systematic review. University of Mississippi Medical Center.

Whisman, M. A., Beach, S. R., \& Snyder, D. K. (2008). Is marital discord taxonic and can taxonic status be assessed reliably? Results from a national, representative sample of married couples. Journal of Consulting and Clinical Psychology, 76, 745-755. https:// doi.org/10.1037/0022-006X.76.5.745

Wildeman, C. (2010). Paternal incarceration and children's physically aggressive behaviors: Evidence from the fragile families and child wellbeing study. Social Forces, 89(1), 285-309

Wiley, L. F. (2014). Health law as social justice. Cornell Journal of Law and Public Policy, 24(1), 47-106

Williams, T., \& Ivory, D. (April 8, 2020). Chicago's jail is top U.S. hot spot as virus spreads behind bars. The New York Times. https:// www.nytimes.com/2020/04/08/us/coronavirus-cook-county-jailchicago.html.

Woods, S. (2020). COVID-19 and ambiguous loss: Stress in the face of a pandemic can take the shape of frozen grief. Psychology Today. https://www.psychologytoday.com/us/blog/in-sickness-and-inhealth/202005/covid-19-and-ambiguous-loss.

Wrape, E. R., \& McGinn, M. M. (2019). Clinical and ethical considerations for delivering couple and family therapy via telehealth. Journal of Marital \& Family Therapy, 45(2), 296-308. https:// doi.org/10.1111/jmft.12319

Yan, J., Schoppe-Sullivan, S. J., \& Feng, X. (2019). Trajectories of mother-child and father-child relationships across middle childhood and associations with depressive symptoms. Development and Psychopathology, 31, 1381-1393. https://doi.org/10.1017/ S0954579418000809

Zeng, Z. (2020). Jail inmates in 2018. US Bureau of Justice Statistics.

Publisher's Note Springer Nature remains neutral with regard to jurisdictional claims in published maps and institutional affiliations. 